\title{
Glycogen Storage Disease Type III diagnosis and management guidelines
}

\author{
Priya S. Kishnani, MD ${ }^{I}$, Stephanie L. Austin, MS, MA ${ }^{I}$, Pamela Arn, MD ${ }^{4}$, Deeksha S. Bali, PhD ${ }^{I}$, \\ Anne Boney, MED, RD, $L D N^{1}$, Laura E. Case, PT, DPT, MS, PCS ${ }^{2}$, Wendy K. Chung, MD, PhD ${ }^{5}$, \\ Dev M. Desai, $M D^{6}$, Areeg El-Gharbawy, $M D^{1}$, Ronald Haller, $M D^{7}$, G. Peter A. Smit, MD, PhD', \\ Alastair D. Smith, MB, ChB ${ }^{3}$, Lisa D. Hobson-Webb, MD ${ }^{3}$, Stephanie Burns Wechsler, $M D^{I}$, \\ David A. Weinstein, MD, MMSc ${ }^{9}$, and Michael S. Watson, PhD ${ }^{10}$
}

\begin{abstract}
Disclaimer: ACMG standards and guidelines are designed primarily as an educational resource for medical geneticists and other health care providers to help them provide quality medical genetic services. Adherence to these standards and guidelines does not necessarily ensure a successful medical outcome. These standards and guidelines should not be considered inclusive of all proper procedures and tests or exclusive of other procedures and tests that are reasonably directed to obtaining the same results. In determining the propriety of any specific procedure or test, the geneticists should apply their own professional judgment to the specific clinical circumstances presented by the individual patient or specimen. It may be prudent, however, to document in the patient's record the rationale for any significant deviation from these standards and guidelines.
\end{abstract}

\begin{abstract}
Purpose: Glycogen storage disease type III is a rare disease of variable clinical severity affecting primarily the liver, heart, and skeletal muscle. It is caused by deficient activity of glycogen debranching enzyme, which is a key enzyme in glycogen degradation. Glycogen storage disease type III manifests a wide clinical spectrum. Individuals with glycogen storage disease type III present with hepatomegaly, hypoglycemia, hyperlipidemia, and growth retardation. Those with type IIIa have symptoms related to liver disease and progressive muscle (cardiac and skeletal) involvement that varies in age of onset, rate of disease progression, and severity. Those with type IIIb primarily have symptoms related to liver disease. This guideline for the management of glycogen storage disease type III was developed as an educational resource for health care providers to facilitate prompt and accurate diagnosis and appropriate management of patients. Methods: An international group of experts in various aspects of glycogen storage disease type III met to review the evidence base from the scientific literature and provided their expert opinions. Consensus was developed in each area of diagnosis, treatment, and management. Results: This management guideline specifically addresses evaluation and diagnosis across multiple organ systems (cardiovascular, gastrointestinal/nutrition, hepatic, musculoskeletal, and neuromuscular) involved in glycogen storage disease type III. Conditions to consider in a differential diagnosis stem-
\end{abstract}

\footnotetext{
From the Departments of ${ }^{1}$ Pediatrics, ${ }^{2}$ Community and Family Medicine, and ${ }^{3}$ Medicine, Duke University Medical Center, Durham, North Carolina; ${ }^{4}$ Department of Pediatrics, Nemours Children's Clinic, Jacksonville, Florida; ${ }^{5}$ Department of Pediatrics, Columbia University Medical Center, New York, New York; ${ }^{6}$ Departments of Surgery and Pediatrics, ${ }^{7}$ Departments of Neurology and Internal Medicine, University of Texas Southwestern Medical Center, Dallas, Texas; ${ }^{8}$ Department of Pediatrics, University Medical Center Groningen, Groningen, The Netherlands; ${ }^{9}$ Department of Pediatrics, University of Florida College of Medicine, Gainesville, Florida; ${ }^{10}$ American College of Medical Genetics, Bethesda, Maryland.
}

Priya S. Kishnani, MD, Duke University Medical Center, Box 103856 DUMC, Durham, North Carolina. E-mail: kishn001@mc.duke.edu.

Disclosure: The authors declare no conflict of interest.

DOI: $10.1097 /$ GIM.0b013e3181e655b6 ming from presenting features and diagnostic algorithms are discussed. Aspects of diagnostic evaluation and nutritional and medical management, including care coordination, genetic counseling, hepatic transplantation, and prenatal diagnosis, are addressed. Conclusions: A guideline that will facilitate the accurate diagnosis and appropriate management of individuals with glycogen storage disease type III was developed. This guideline will help health care providers recognize patients with all forms of glycogen storage disease type III, expedite diagnosis, and minimize stress and negative sequelae from delayed diagnosis and inappropriate management. It will also help identify gaps in scientific knowledge that exist today and suggest future studies. Genet Med 2010:12(7):446-463.

Key Words: glycogen storage disease type III, Cori disease, Forbes disease, limit dextrinosis, debranching enzyme deficiency, management guidelines.

\section{PURPOSE}

This guideline is intended as an educational resource. It highlights current practices and therapeutic approaches to the diagnosis and management of the multiple complications of glycogen storage disease (GSD) type III.

\section{GENERAL BACKGROUND}

\section{History}

In 1952, Barbara Illingworth and Gerty Cori ${ }^{1}$ discovered excessive amounts of abnormally structured glycogen in liver and muscle from a patient whom Gilbert Forbes ${ }^{2}$ was following up clinically. Because the stored glycogen had short outer chains, as in a phosphorylase-limit dextrin, it was suspected that there was a deficiency of the enzyme amylo-1,6-glucosidase (AGD); this prediction was confirmed in 1956. ${ }^{3}$ Deficiency of the enzyme, also called glycogen debranching enzyme (GDE), results in GSD III, which is also referred to as "limit dextrinosis," "Cori," or "Forbes" disease. 
Most individuals with GSD III survive into adulthood as in the case of the two patients (a male and a female) originally reported by Snappes and Van Creveld in $1928 .{ }^{4}$ Both patients had hepatomegaly and inability to mobilize liver glycogen. Both patients improved clinically with the hepatomegaly resolving after puberty, a common finding in affected individuals. In 1964, Van Creveld and Huijing ${ }^{5}$ demonstrated that these two patients had deficient debranching enzyme activity. It was further shown that although debranching enzyme, or AGD, was present in leukocytes of normal individuals, no AGD was found in the leukocytes of individuals with GSD caused by debranching enzyme deficiency. ${ }^{6}$

The human debranching enzyme gene is a large single-copy gene (GenBank M85168) located on chromosome 1p21, which was cloned in 1991 by Yang et al. ${ }^{7}$ The human debranching enzyme gene spans $85 \mathrm{~kb}$ and contains 35 exons, encoding a 7.0-kb mRNA. ${ }^{8}$ Six mRNA isoforms are present, differing in the $5^{\prime}$ untranslated region and tissue distribution because of differential transcription and alternative exon usage of a single debranching-enzyme gene. ${ }^{9}$ The major mRNA isoform present in both muscle and liver encodes a protein consisting of 1532 amino acid residues.

\section{Overview and general background}

GDE is one of the few known proteins with two independent catalytic activities occurring at separate sites on a single polypeptide chain. The two activities are transferase (1,4- $\alpha$-Dglucan; 1,4- $\alpha$-D-glucan 4- $\alpha$-D-glycosyltransferase) and AGD. Both debranching enzyme and phosphorylase enzyme are needed for the complete degradation of glycogen. Clinical symptoms attributable to impaired degradation and increased glycogen accumulation include hepatic dysfunction and disease (hypoglycemia, pronounced hepatomegaly, and cirrhosis), variable skeletal myopathy, variable cardiomyopathy, and poor growth. Laboratory findings include increased liver enzyme levels, hypoglycemia, hyperlipidemia, and ketosis. The level of serum creatine kinase (CK) may be increased in individuals with muscular/cardiac involvement.

Type III GSD is an autosomal recessive disease that has been reported in many different ethnic groups including Caucasians, Africans, Hispanics, and Asians. The frequency of the disease is relatively high in Sephardic Jews of North African extraction (prevalence 1:5400).

Individuals with this disease vary remarkably, both clinically and enzymatically. ${ }^{10,11}$ Most have disease involving both liver and muscle (type IIIa), some ( $\sim 15 \%$ of all those with GSD-III) have only liver involvement (type IIIb), and in rare cases, there is a selective loss of only one of the two GDE activities: glucosidase (type IIIc) or transferase (type IIId). GSD IIIc affects only the muscle, and GSD IIId affects the muscle and the liver. ${ }^{12}$ The latter two are extremely rare with only a handful of cases reported. ${ }^{11,13,14}$

\section{Clinical history}

During infancy and childhood, the dominant features are hepatomegaly, hypoglycemia, hyperlipidemia, and growth retardation. In individuals with muscle involvement (GSD IIIa), there is variable myopathy and cardiomyopathy. Serum CK levels can be useful to identify individuals with muscle involvement; however, normal CK levels do not rule out muscle enzyme deficiency. ${ }^{15}$

Hepatomegaly and hepatic symptoms in most individuals with type III GSD improve with age and usually resolve after puberty. ${ }^{16}$ The apparent improvement may be related to a reduced relative glucose requirement. The decrease in liver size can be misleading as progressive liver cirrhosis and hepatic failure can occur, and some individuals develop end-stage liver cirrhosis. ${ }^{16-20}$ Hepatic adenomas have been reported with a prevalence ranging from $4 \%$ to as high as $25 \% .{ }^{17}$ There are also reports of hepatocellular carcinoma (HCC). ${ }^{18}$ In rare instances, hepatic symptoms may be mild, and the diagnosis is not made until adulthood when the individuals manifest symptoms and signs of neuromuscular disease. ${ }^{21}$

Muscle involvement in GSD IIIa is variable; some individuals have asymptomatic cardiomyopathy, some have symptomatic cardiomyopathy leading to death, and others have only skeletal muscle and no apparent heart involvement. Ventricular hypertrophy is a frequent finding, but overt cardiac dysfunction is rare. ${ }^{22-25}$ Sudden death thought to be caused by cardiac arrhythmias has been reported. ${ }^{23,26,27}$ There may be motor delays in childhood, weakness and wasting may slowly progress and become severe by the 3rd or 4th decade of life. ${ }^{16}$ Myopathy can be both proximal and distal. Electromyography (EMG) reveals a widespread myopathy; nerve conduction studies may also be abnormal. ${ }^{28,29}$ Individuals with GSD III may be at increased risk for osteoporosis, especially those with muscle involvement. ${ }^{30}$ Polycystic ovaries are common, ${ }^{31}$ but fertility is not reduced. There have been reports of successful pregnancies in individuals with GSD III. ${ }^{32-34}$

\section{METHODS/PROCESS}

\section{Consensus development panel}

An international group of experts in (a) clinical and laboratory diagnosis, (b) treatment and management (cardiac, gastrointestinal/dietary, musculoskeletal, neurologic, psychosocial, hepatic transplantation, general medical, and supportive and rehabilitative); and (c) genetic aspects of GSD III was assembled to review the evidence base and develop management guidelines. After a meeting during which published material and personal experience were reviewed by the panel, experts in the various areas reviewed the literature in these areas and drafted the guidelines. Conflict of interest statements were provided by the participants. All members of the panel reviewed and approved the final guidelines. Consensus was defined as agreement among all members of the panel. For the most part, the evidence and resulting recommendations are considered expert opinion because additional levels of evidence were not available in the literature. Penultimate drafts of these guidelines were shared with an external review group consisting of Salvatore DeMauro, MD, William Rhead, MD, Lane Rutledge, MD, Mark Tarnopolsky, MD, PhD, Joseph Wolfsdorf, MB, BCh, and Yuan-Tsong Chen, MD, PhD. Their suggestions were considered by the working group, and changes were made as considered appropriate.

\section{Target audience}

This guideline is directed at a wide range of providers. Although care is commonly provided by metabolic disease specialists/biochemical geneticists, gastroenterologists and neuromuscular experts, it is important that primary care providers and other specialists who often are involved in the care of these patients with GSD III also be able to recognize the condition and to provide appropriate care for these patients.

\section{DIAGNOSTIC CONFIRMATION}

\section{Differential diagnosis}

Type III GSD has variable symptoms depending on the severity and tissues and organs involved. ${ }^{35,36}$ As a result, the 
Table 1 Differential diagnosis of GSD III

\begin{tabular}{|c|c|c|}
\hline Disorder & Similarity with GSD III & Distinguishing features \\
\hline $\begin{array}{l}\text { GSD type } 0 \text { (glycogen synthase } \\
\text { deficiency) }\end{array}$ & Fasting hypoglycemia and ketosis & Absence of hepatomegaly \\
\hline $\begin{array}{l}\text { GSD type I (glucose-6- } \\
\text { phosphase deficiency) }\end{array}$ & $\begin{array}{l}\text { Severe hypoglycemia and } \\
\text { hyperlipidemia }\end{array}$ & $\begin{array}{l}\text { Increased uric acid, increased lactate, lack of severe ketones, } \\
\text { nephromegaly, and lack of muscle symptoms }\end{array}$ \\
\hline $\begin{array}{l}\text { GSD type II (acid alpha } \\
\text { glucosidase deficiency) }\end{array}$ & $\begin{array}{l}\text { Myopathy-elevated CK, AST, } \\
\text { and ALT levels }\end{array}$ & $\begin{array}{l}\text { Lack of liver symptoms, AST usually higher than ALT, } \\
\text { diaphragm involvement, proximal myopathy with distal } \\
\text { sparing until late in disease course, and lysosomal glycogen } \\
\text { on histology }\end{array}$ \\
\hline $\begin{array}{l}\text { GSD type IV (hepatic } \\
\text { presentation; branching } \\
\text { enzyme deficiency) }\end{array}$ & $\begin{array}{l}\text { Hepatomegaly, elevated AST, } \\
\text { ALT levels }\end{array}$ & $\begin{array}{l}\text { Lack of hypoglycemia until end-stage liver disease, } \\
\text { polyglucosan storage on muscle biopsy }\end{array}$ \\
\hline $\begin{array}{l}\text { GSD type IV (neuromuscular } \\
\text { presentation; branching } \\
\text { enzyme deficiency) }\end{array}$ & Increased CK, myopathy & $\begin{array}{l}\text { Hypotonia, amylopectin-like inclusions, muscle atrophy, } \\
\text { respiratory insufficiency, and sometimes dilated } \\
\text { cardiomyopathy or neuronal involvement }\end{array}$ \\
\hline GSD $\mathrm{V}$ and VII & $\begin{array}{l}\text { Muscle glycogen storage, } \\
\text { increased CK }\end{array}$ & $\begin{array}{l}\text { Dynamic symptoms of exertional muscle contractures and } \\
\text { rhabdomyolysis }\end{array}$ \\
\hline $\begin{array}{l}\text { GSD type VI (phosphorylase } \\
\text { deficiency) }\end{array}$ & $\begin{array}{l}\text { Hepatomegaly, elevated AST and } \\
\text { ALT levels, hypoglycemia }\end{array}$ & Lack of muscle involvement, usually less severe clinically \\
\hline $\begin{array}{l}\text { GSD type IX (phosphorylase } \\
\text { kinase deficiency, liver forms) }\end{array}$ & $\begin{array}{l}\text { Hepatomegaly, elevated AST and } \\
\text { ALT levels, } \\
\text { hypoglycemia } \pm \text { elevated CK }\end{array}$ & $\begin{array}{l}\text { X-linked form typically less severe clinically, other liver } \\
\text { forms (Gamma2 variant and AR forms) can be more rapidly } \\
\text { progressive, variability between and within different } \\
\text { subtypes }\end{array}$ \\
\hline $\begin{array}{l}\text { Disorders of fructose metabolism } \\
\text { (hereditary fructose } \\
\text { intolerance) }\end{array}$ & $\begin{array}{l}\text { Hepatomegaly, elevated AST and } \\
\text { ALT levels }\end{array}$ & $\begin{array}{l}\text { Gastrointestinal symptoms long-term liver and kidney damage, } \\
\text { prolonged clotting time, hypoalbuminemia, elevation of } \\
\text { bilirubin, and proximal tubular dysfunction, hypoglycemia } \\
\text { provoked by fructose intake }\end{array}$ \\
\hline GSD type XI (Glut-2 deficiency) & $\begin{array}{l}\text { Hepatomegaly, elevated AST and } \\
\text { ALT levels, hypoglycemia }\end{array}$ & $\begin{array}{l}\text { Gastrointestinal symptoms, renal symptoms such as renal } \\
\text { tubular acidosis }\end{array}$ \\
\hline $\begin{array}{l}\text { Disorders of gluconeogenesis } \\
\text { (e.g., fructose } 1-6 \\
\text { diphosphatase deficiency) }\end{array}$ & $\begin{array}{l}\text { Hepatomegaly, elevated AST and } \\
\text { ALT levels, hypoglycemia }\end{array}$ & Lactate elevation with fasting \\
\hline $\begin{array}{l}\text { Primary liver diseases (alpha-1- } \\
\text { antitrypsin, hepatitis) }\end{array}$ & $\begin{array}{l}\text { Hepatomegaly, elevated AST and } \\
\text { ALT levels }\end{array}$ & Lack of fasting hypoglycemia and ketosis \\
\hline $\begin{array}{l}\text { Other metabolic disorders } \\
\text { (Niemann Pick B, Gaucher) }\end{array}$ & $\begin{array}{l}\text { Hepatomegaly, growth failure, } \\
\text { hyperlipidemia }\end{array}$ & $\begin{array}{l}\text { Presence of significant splenomegaly, lack of hypoglycemia, } \\
\text { presence of storage cells characteristic for the disease }\end{array}$ \\
\hline
\end{tabular}

differential diagnosis of type III is extensive (Table 1), and a well-planned diagnostic approach is required. The most common alternative diagnosis in the differential is GSD type Ia. Features common to both disorders are hepatomegaly, hyperlipidemia, and hypoglycemia. However, some key differences between GSD I and III help differentiate these two disorders. Individuals with GSD I typically present earlier (in the first few months of life) with severe fasting hypoglycemia 3 to 4 hours after a feed. In individuals with GSD III, hypoglycemia is usually not as severe as in GSD I because of intact gluconeogenesis and the ability to metabolize peripheral branches of glycogen via phosphorylase. Nonetheless, there are cases of GSD III whose clinical onset is similar to that of GSD I. ${ }^{37}$ Laboratory features that further help to distinguish between these disorders are elevated uric acid and lactate concentrations in GSD I, which are typically normal in GSD III. ${ }^{38}$ GSD III is associated with higher hepatic transaminase concentrations than GSD I, and aspartate aminotransferase (AST)/alanine aminotransferase (ALT) concentrations exceeding $500 \mathrm{U} / \mathrm{L}$ are commonly seen.
Ultrasound imaging of the liver at baseline is similar in GSD I and GSD III, but the presence of nephromegaly in GSD type I can be a clue to the diagnosis. ${ }^{39}$ A controlled fasting study can further help distinguish GSD III from GSD I. Blood lactate concentrations rise rapidly in GSD type I as soon as hypoglycemia develops, whereas hyperketonemia with fasting is suggestive of GSD III. ${ }^{40,41}$

Although transaminase elevation and hepatomegaly are common to many primary hepatic diseases and other metabolic disorders, hypoglycemia is uncommon until the development of end-stage liver disease (ESLD) for most disorders except GSDs. ${ }^{42,43}$ The extent of the hepatomegaly is similar in types VI and IX GSD, and all of these (GSD III, VI, and IX) can have profound ketosis after an overnight fast. The extent of the hypoglycemia, transaminase elevation, and hyperlipidemia are usually more severe in GSD III; however, severely affected individuals with GSD VI and GSD IX are being increasingly recognized. GSD type IV does not have hypoglycemia or ketone abnormalities until reaching end 
stage, and liver dysfunction is usually more pronounced in GSD IV. 44

Muscle involvement and elevated CK concentrations can occur in GSD IIIa, some hepatic forms of GSD IX, McArdle disease, and late onset GSD II (Pompe disease) but with clinical and pathophysiologic differences. Muscle weakness in late onset Pompe disease is primarily truncal and proximal, affecting lower more than upper limbs; diaphragm weakness is common and may be the presenting symptom; and hepatomegaly or hypoglycemia are absent. In GSD III, muscle weakness can be both proximal and distal, is accompanied by hypoglycemia and hepatomegaly in children, does not affect muscles involved in respiration, and is usually not noted before presentation with hypoglycemia and/or hepatomegaly. Respiratory distress caused by involvement of the diaphragm is highly suggestive of Pompe disease and can be a key distinguishing feature not only from GSD III but also from other neuromuscular disorders. ${ }^{45}$ Limb-girdle muscular dystrophy, inflammatory myopathy, myasthenia gravis, motor neuron disease, and Pompe disease (GSD II) could be included in the differential diagnosis of adults presenting with weakness. Individuals with McArdle disease may have significantly elevated CK levels together with exercise-induced muscle cramps and are prone to develop rhabdomyolysis. These features help to distinguish it from GSD III. Myopathic motor unit potentials along with the presence of spontaneous activity on EMG may suggest a myositis, but this pattern is often seen with glycogen storage disorders, such as Pompe disease and GSD III.

Rarely, a severe infantile cardiomyopathy can occur in GSD III, ${ }^{23}$ which can be difficult to distinguish from Pompe disease and Danon disease. In these primary cardiac disorders, hypoglycemia is not present. There may be hepatomegaly caused by cardiac failure. A rare variant of phosphorylase kinase deficiency caused by mutations in the PRKAG2 gene can also present with severe infantile hypertrophic cardiomyopathy. ${ }^{46}$

Other metabolic disorders such as Gaucher disease and Niemann-Pick disease may, initially, be confused with GSD because of the presence of hepatomegaly. In these storage disorders, however, splenomegaly is massive and helps in the differential diagnosis. ${ }^{43}$ Hypoglycemia can also be used to distinguish GSD from other metabolic abnormalities.

\section{Clinical and laboratory evaluation}

In GSD III, the administration of glucagon 2 hours after a carbohydrate-rich meal provokes a normal increase in blood glucose (BG), whereas, after an overnight fast, glucagon typically provokes no change in BG level.

Critical blood samples drawn at the time of hypoglycemia are useful in evaluation of the various metabolic and endocrine causes (Table 2). The coexistence of hepatomegaly and hypoglycemia should prompt a workup that includes measurement of $\mathrm{BG}$, lactate, uric acid, and hepatic profile including liver function studies, CK, plasma total and free carnitine, acylcarnitine profile, urinalysis, and urine organic acids. When the diagnosis is unclear, measurement of insulin, growth hormone, cortisol, free fatty acids, beta-hydroxybutyrate, and acetoacetate levels may also be needed. In addition, the results of newborn screening should be checked because fatty acid oxidation disorders and galactosemia are included both in the differential diagnosis and standard newborn screening panels. At presentation, individuals with GSD III have elevated transaminase levels, often $>2 \times$ upper limits of normal and often $>500 \mathrm{IU} / \mathrm{L}$, with elevated fatty acid concentrations. At the time of hypoglycemia, beta-hydroxybutyrate concentration will be elevated, which is in contrast to the hypoketosis characteristic of fatty acid oxidation
Table 2 Suggested laboratory evaluations for a patient with hypoglycemia and hepatomegaly

$\begin{array}{ll}\begin{array}{l}\text { Primary evaluation } \\ \text { (if possible, drawn } \\ \text { at the time of } \\ \text { hypoglycemia) }\end{array} & \text { Blood glucose } \\ & \text { Blood lactate } \\ & \begin{array}{c}\text { Hepatic acid } \\ \text { function studies } \\ \text { Serum lipid profile }\end{array} \\ & \text { Plasma CK } \\ & \text { Plasma total and free carnitine } \\ & \text { Plasma acylcarnitine profile } \\ & \text { Plasma amino acids } \\ & \text { Urinalysis } \\ & \text { Urine organic acids } \\ \text { Insulin } \\ \begin{array}{l}\text { Secondary evaluation } \\ \text { diagnosis is }\end{array} \\ \text { unclear) }\end{array}$

disorders and hyperinsulinism. A more detailed workup of the individual who presents with hypoglycemia and hepatomegaly can be found in Scriver's Online Metabolic and Molecular Bases of Inherited Disease. ${ }^{47}$

Electromyograms and nerve conduction studies are generally both abnormal showing evidence of myopathy (small, short duration motor units) and a mixed pattern of myopathy and neuropathy. ${ }^{28}$ These findings may be caused by structurally abnormal glycogen accumulation within the skeletal muscle and peripheral nerves. ${ }^{48}$ Although rarely performed in the clinical scenario of GSD III, forearm exercise testing will demonstrate a blunted increase in lactate in GSD III. ${ }^{49}$ Uric acid levels could also be elevated in the setting of muscle exertion. ${ }^{50}$

Hepatomegaly and/or myopathy often lead gastroenterologists and neurologists to biopsy the liver or muscle/nerve to differentiate among the diverse causative factors in the differential diagnosis. Biopsies should lead to a definitive diagnosis in most cases but are critically dependent on the site of the biopsy and correct processing of the tissue. Tissues should be processed for light microscopy and electron microscopy, and also snap frozen $(\sim 15 \mathrm{mg})$ in the operating room in liquid nitrogen for biochemical analysis. Usually $30-40 \mathrm{mg}$ of tissue or four cores of liver tissue are required for all the studies necessary to make a definitive diagnosis. In the United States, reliable enzymatic analysis is only available on frozen muscle and liver biopsy samples.

Liver histology in those with GSD III can help differentiate it from other liver GSDs. Histopathologic findings of the liver in GSD I include distention of the liver cells by glycogen and fat with uniform glycogen distribution. ${ }^{51}$ There is a mosaic pattern with pale staining and nuclear hyperglycogenation. Lipid vacuoles are large and frequent. ${ }^{52}$ In most individuals with GSD III, the liver and/or muscle biopsy demonstrate a vacuolar accumu- 
lation of nonmembrane-bound glycogen primarily located in the cytoplasm. Lipid vacuoles are less frequent in GSD III than in GSD I. The presence of fibrosis, ranging from minimal periportal fibrosis to micronodular cirrhosis, is noted in GSD III and not in GSD I. ${ }^{16,51,52}$ Some glycogen is also found in lysosomes. ${ }^{21,53,54}$ The stored material in GSD I and III is periodic acid-Schiff positive and diastase sensitive within the cytoplasm.

With thorough noninvasive routine laboratory testing, it is often possible to arrive at a presumptive diagnosis of GSD III without a biopsy. However, definitive testing for GSD IIIa via either molecular genetic or enzymatic testing is necessary.

\section{DIAGNOSTIC TESTING}

\section{Glycogen debranching enzyme}

GDE is an unusual protein because of its two independent catalytic activities; 1,4-alpha-D-glucan 4-alpha-D-glycosyltransferase and AGD, with separate active sites on a single polypeptide chain. 55

\section{Laboratory diagnosis of GSD III}

A diagnosis of GSD III is based on: (i) demonstration of excessive and structurally abnormal glycogen accumulation with shorter outer branches and deficient debranching enzyme activity in frozen liver and/or muscle biopsy samples or (ii) identification of pathogenic mutations in the $A G L$ gene on both alleles.

\section{Biochemical analysis of GDE activity and glycogen content}

Clinical assays measure overall GDE activity in the affected tissue samples. The glycogen content is markedly increased in GSD III (as high as 3 to 5 times the normal levels), and the accumulated glycogen appears structurally abnormal (shorter outer branches; indicated by decreased G-1-P to glucose ratio as compared with normal controls). This is an important distinguishing feature for GSD III compared with other GSDs (II, IV, $\mathrm{V}, \mathrm{VI}$, and IX) where glycogen content may be elevated but glycogen structure is normal. ${ }^{56-58}$ Of note, in GSD I, the total glycogen content is much lower than in GSD II, III, V, VI and IX (Table 3).

The pattern of GDE deficiency in different tissues determines the specific subtype of GSD III. Individuals with GSD IIIa have deficient enzyme activity in both liver and muscle, whereas those with GSD IIIb have enzyme deficiency limited to the liver. Thus, for a definitive diagnosis of GSD III, muscle biopsy is usually necessary to distinguish GSD IIIa from IIIb, although the finding of mutations specific to GSD IIIb can help in this regard (see below). Some rare cases of GSD IIIc (isolated glucosidase deficiency) and IIId (isolated transferase deficiency) where there is a selective loss of only one of the two GDE activities have also been reported. However, these selective enzyme deficiencies are extremely rare with only a handful of reported cases; thus, their correlation with liver and/or muscle tissues has not been well understood. The molecular basis of tissue-specific GDE activity in individuals with the various subtypes of GSD III is also poorly understood.

GDE deficiency has also been demonstrated in blood cells and skin fibroblasts, but these assays are not clinically available in the United States. Western blot analysis has also been used to prove the absence of GDE protein in erythrocytes, leukocytes, lymphoblastoid cells, and skin biopsy samples for cultured skin fibroblasts from individuals with GSD III. ${ }^{13,51,59-62}$ Similarly, these tests are not available for clinical use.

Prenatal diagnosis based on measurement of enzyme activity in cultured chorionic villus cells or amniocytes is possible but not clinically available. Prenatal diagnosis has also been performed by immunoblot. 7,13,59,61,63,64 The availability of fullgene sequencing of the $A G L$ gene and knowledge of family's pathogenic mutations has greatly facilitated prenatal diagnosis of GSD type III (see below).

\section{DNA mutation analysis}

GSD IIIa and IIIb are allelic disorders. Mutation testing can help confirm the diagnosis and provide information to predict GSD III subtype, carrier testing, and prenatal or preimplantation genetic diagnosis.

Mutations causing GSD IIIa are scattered throughout the $A G L$ gene and are associated with considerable allelic heterogeneity. All mutation types, including missense, nonsense, splice site, small frame shift deletions and insertions, and large gene deletions and duplications, have been described in the $A G L$ gene. Most mutations are specific to individual families although there are some common mutations associated with specific ethnic backgrounds. ${ }^{65}$ In the United States, p.R864X $(10.3 \%), \quad$ c.3964delT $(6.7 \%), \quad$ c.4260-12G $>$ A (IVS32$12 \mathrm{~A}>\mathrm{G})(5.5 \%)$, and p.R $1228 \mathrm{X}(5.2 \%)$ are the most common mutations but together account for only $28 \%$ of all mutant alleles. $55,57,66,67$

Unlike GSD IIIa, which is associated with allelic heterogeneity, two mutations in exon 3-c.18_19delGA (p.Gln6HisfsX20), for-

Table 3 Biochemical and histologic characteristics of selected GSD types

\begin{tabular}{lll}
\hline & $\begin{array}{c}\text { Biochemical characteristics (glycogen content/ratio } \\
\text { of glucose-1 phosphate/glucose) }\end{array}$ & \\
\hline GSD I & Upper limit of normal/normal & PAS-positive cytoplasmic glycogen and a significant lipid accumulation \\
GSD II & Extremely elevated/normal & PAS-positive vacuolated membrane-bound lysosomal glycogen \\
GSD III & Extremely elevated/decreased & PAS-positive cytoplasmic glycogen mixed with some lipid accumulation \\
GSD IV & Slightly elevated/normal to increased & PAS-positive/diastase resistant amylopectin-like cytoplasmic glycogen \\
GSD V & Extremely elevated/normal & PAS-positive cytoplasmic glycogen \\
GSD VI & Extremely elevated/normal & PAS-positive cytoplasmic glycogen \\
GSD VII & Slightly elevated/normal & PAS-positive, some amylopectin-like cytoplasmic glycogen \\
GSD IX & Extremely elevated/normal & PAS-positive cytoplasmic glycogen
\end{tabular}


merly described as c.17_18delAG, and c.16C $>$ T (p.Gln6X) —are specifically associated with the GSD IIIb phenotype. ${ }^{66}$ Both these mutations are predicted to result in severely truncated proteins with absent GDE activity. However, the mechanism by which these mutations result in retained muscle GDE activity is unknown. However, failure to identify an exon 3 mutation in an individual without myopathic symptoms at the time of presentation does not confirm the diagnosis of GSD IIIa. Other than the association between the two exon 3 mutations and GSD IIIb, no strong genotype-phenotype correlations exist for GSD type III. Previous reports suggest that some mutations are associated with a severe phenotype including c.3965delT and c.4529insA, ${ }^{22,57,68}$ whereas other mutations such as the splice site mutation c.4260-12A $>\mathrm{G}$ (IVS32-12A $>$ G) seem to confer a milder phenotype when present in the homozygous state. ${ }^{57,68}$ Although not definitive, data suggest that individuals with null mutations are more likely to develop more severe disease. ${ }^{69}$

Considering the large size of the $A G L$ gene ( 35 exons and 33 coding exons) and the marked genetic heterogeneity observed a mutation screening strategy has been suggested.55 If GSD IIIb is strongly suspected, exon 3 may be sequenced first since identification of at least one exon 3 common mutation predicts a GSD IIIb phenotype and may obviate the need for more comprehensive and expensive sequencing or a muscle biopsy for enzyme analysis. If the individual has muscle involvement, screening for ethnic group specific mutations may be appropriate. Full $A G L$ gene sequencing (which is clinically available) should be performed if targeted mutation analysis fails to reach a diagnosis. If only one mutation is identified, deletion/duplication testing is recommended.

\section{OVERVIEW OF MANAGEMENT}

GSD III disease is a multisystem disorder best managed by a multidisciplinary team led by an experienced physician. Team members should include a metabolic disease specialist/biochemical geneticist in addition to the specialists dictated by the disease manifestations. This might include a cardiologist, neuromuscular specialist, gastroenterologist, physical therapist, occupational therapist, genetic counselor, and a metabolic dietitian. All specialists involved in the care of an individual with GSD III should have an understanding of the disease, its broad and protean manifestations, and its challenges, including the psychologic and emotional impact of this disease on patients and families. There should be a team member with experience in GSD III (e.g., the metabolic specialist) who is able to coordinate the patient's care.

\section{CARDIOLOGY}

Glycogen deposition in cardiac muscle has been recognized since $1968^{70}$; however, the amount of glycogen was thought to be insignificant and to have little clinical effect, especially when compared with the cardiac hypertrophy with heart failure and death observed in individuals with infantile Pompe disease (GSD II). An early case report in 1972 by Miller et al. ${ }^{23}$ described an infant with GSD III who died suddenly at the age of 4 months and, at autopsy, showed striking cardiac hypertrophy. Another case report in 1984 described a young woman with GSD III who developed symptomatic congestive heart failure during pregnancy and also had cardiac hypertrophy with glycogen deposition documented by heart biopsy. ${ }^{71}$ Thus, cardiac involvement in GSD III is not just an incidental finding, but the extent of involvement of the heart remains an important clinical question. The report in 1984 first suggested that serial echocardiograms might be able to identify individuals with GSD III who have cardiac involvement and are at risk of symptomatic congestive heart failure.

\section{Ventricular hypertrophy and cardiomyopathy}

Individuals with GSD III do not develop valvular disease such as semilunar or atrioventricular valve regurgitation, but left ventricular hypertrophy (LVH) seems to be common in GSD III, although only a small fraction of individuals with GSD III actually develop cardiomyopathy (symptomatic ventricular hypertrophy). Several small case series reported in 1989 and 1997 suggested that ventricular hypertrophy is a relatively common finding in GSD III, although the exact incidence was quite variable, between $30 \%$ and $80 \%$, depending on the study. ${ }^{15,24,25,72-74}$ There are rare reports of GSD III patients with symptomatic cardiomyopathy, $23,26,71,75-76$ and one patient with congestive heart failure required a cardiac transplant. ${ }^{77}$ Predictive features for those who may have a worse cardiac outcome are unknown. No correlation with myopathy or CK activity has been noted. ${ }^{15,22,73}$ There is some indica-

\section{LABORATORY DIAGNOSTIC TESTING RECOMMENDATIONS}

- Marked elevation of glycogen content in affected tissues with structurally abnormal glycogen (reduced glucose-1-P/glucose) is consistent with GSD type III

- Diagnosis is confirmed by demonstrating deficiency of GDE enzyme in liver and/or muscle or by gene sequencing

- GSD III is subtyped by the pattern of GDE deficiency in liver and muscle

- Presence of one of the two common exon 3 mutation is associated with GSD IIIb phenotype

- Targeted mutation analysis for prenatal diagnosis and carrier testing or patient diagnosis can be performed if clear knowledge of specific private family mutations and/or common mutations for specific ethnic groups is available 
tion that LVH may become more common with age, although it is clear that LVH alone does not indicate clinically significant cardiomyopathy. ${ }^{15,72}$

Endomyocardial biopsy specimens show glycogen deposition but no myocyte disarray, which contrasts with the histologic hallmark of myocyte disarray seen in hypertrophic cardiomyopathy because of sarcomeric mutations, despite the similar appearance of hypertrophy on echo imaging. ${ }^{71}$ The echo imaging of individuals with GSD III reported to date has been relatively limited in scope, showing mostly LV thickness and shortening fraction as the echo parameters measured. More sophisticated echo measurements such as LV mass, as have been studied in Pompe disease, ${ }^{78}$ may better define the increase in LV thickness. Given that diastolic dysfunction is often the first functional abnormality in hypertrophic cardiomyopathy, it usually precedes any systolic dysfunction. There is one case report ${ }^{79}$ that notes echo parameters suggesting $\mathrm{LV}$ diastolic dysfunction in the face of preserved systolic function with normal ejection fraction. Furthermore, longitudinal follow-up of GSD III patients with respect to cardiac involvement has not been reported; however, in this journal, a recent study is included with longitudinal follow-up and LV mass and wall thickness measurements. ${ }^{27}$

\section{Electrophysiology/heart rhythm}

Limited data are available regarding heart rhythm abnormalities in GSD III. Only a few series have reported electrocardiography (ECG) findings and, in most cases, these have shown cardiac hypertrophy. ${ }^{22,24,71,72}$ There is very limited information regarding the potential for arrhythmia, although isolated case reports suggest that arrhythmia can occur. The infant who died suddenly at the age of 4 months with marked ventricular hypertrophy may have died from an arrhythmia. ${ }^{23}$ Moses et al. ${ }^{24}$ included one patient in their series with symptomatic cardiomyopathy and significant LVH by echo who had one documented episode of atrial fibrillation. Vertilus et al. in this issue of Genetics in Medicine also note a few patients who died suddenly, thought to be likely because of arrhythmia. Other than ECG findings suggestive of ventricular hypertrophy, specific rhythm disturbances on ECG appear to be uncommon. Given the known LVH and these case reports, there is the potential for serious arrhythmia.

\section{Atherosclerosis}

Hyperlipidemia, including hypercholesterolemia and hypertriglyceridemia, occurs in as many as $40 \%$ of those with GSD III, ${ }^{74,80}$ although not all studies confirm this finding. ${ }^{81}$ Hyperlipidemia is a well-recognized risk factor for atherosclerosis. Thus, vascular dysfunction with early atherosclerosis or early coronary artery disease could occur in individuals with GSD III. There are limited data to date regarding this clinical question. A report by Hershkovitz et al. ${ }^{81}$ in 1999 described lipid profiles and endothelial dysfunction (assessed by brachial artery responsivity) in a small group of patients with GSD III, aged 10 to 39 years. They found normal lipid profiles and vascular endothelial function, ${ }^{82}$ suggesting that there is no strong association of GSD III with hyperlipidemia or with functional measure of vascular reactivity. More studies are needed to confirm these observations.

\section{Routine evaluation and management}

Based on currently available data regarding cardiovascular involvement in GSD III, several recommendations for evaluation and management can be made. Because ventricular hypertrophy, sometimes associated with cardiomyopathy and clinical symptoms, is well documented in GSD III, routine evaluation of rhythm by ECG and for ventricular hypertrophy by echocardiogram is recommended. Echocardiograms should measure wall thickness and ventricular mass. Echo measurement of systolic function such as shortening fraction and ejection fraction should be performed periodically, but measures of diastolic function are useful as well because diastolic dysfunction may precede overt systolic dysfunction and could indicate the need to begin closer follow-up for potential cardiovascular symptoms. For individuals with GSD IIIa, serial echocardiograms are recommended beginning at the time of diagnosis and repeated every 12-24 months until there is an abnormality by echo or clinical symptoms suggestive of poor ventricular function or arrhythmia. For individuals with GSD IIIb, a baseline echo at the time of diagnosis and then every 5 years seems to be a reasonable screening strategy to monitor cardiac status. Although current knowledge is that individuals with GSD IIIb do not develop cardiac involvement, long-term follow-up of these individuals has not been done, and there are some with GSD IIIb in whom LV mass is at upper limits of normal. ${ }^{27}$ The same parameters of ventricular thickness, ventricular mass, and systolic and diastolic function should also be measured in those with GSD IIIb.

Although potential heart rhythm abnormalities have not been accurately quantified, it seems that arrhythmia can develop in a subset of individuals with GSDIII. It seems prudent to perform serial 12-lead ECGs every other year in individuals with GSD IIIa to examine the heart rhythm. Additional electrophysiologic monitoring is indicated for individuals with clinical symptoms such as palpitations, for individuals in whom an ECG abnormality develops, or for individuals who develop moderate or more severe ventricular hypertrophy by serial echo imaging.

As a general rule, no exercise restrictions are recommended for individuals with GSD III. Although exercise restrictions may be necessary if significant ventricular hypertrophy with ventricular outflow tract obstruction develops or if heart rhythm abnormalities develop (also see section on Physical therapy/ exercise).

\section{GASTROINTESTINAL/NUTRITION}

The type of GSD III (IIIa or IIIb), the age at diagnosis, and the individual's symptoms will determine the best dietary treatment options.

\section{Infants and young children with GSD IIIa and IIIb}

The initial focus of the diet for the infant and young child with either GSD IIIa or IIIb is to prevent hypoglycemia. Small, frequent feedings and the avoidance of fasting are generally agreed on as the first step. There is still controversy regarding the distribution of calories from carbohydrates, protein, and fat. The onset of myopathy (GSD IIIa only) occurs at an earlier age than was once thought; therefore, the importance of protein in the younger child's diet should not be overshadowed by a singular focus on carbohydrates. ${ }^{83-85}$ A high protein diet may be beneficial in three ways: with gluconeogenesis intact, protein-derived alanine can be used as an alternate source for glucose during times of fasting; higher dietary protein intake may also improve muscle function by enhancing muscle protein synthesis; and by replacing some of the carbohydrates with protein, unnecessary glycogen storage may be reduced. The child with myopathy and growth failure should be started on a high protein diet. ${ }^{85,86}$ The child with GSD IIIb may only need cornstarch (CS) therapy ${ }^{87}$; however, the addition of protein may still be beneficial both as an alternate source of glucose and by decreasing the accumulation of abnormally structured glycogen 


\section{CARDIOLOGY RECOMMENDATIONS}

- Echocardiography for ventricular hypertrophy including wall thickness, ventricular mass and systolic and diastolic function

o For GSD IIIa, obtain baseline and repeat every 12-24 months

- For GSD IIIb, obtain baseline echocardiography for the same parameters as noted for GSD IIIa; repeat every 5 years

- Routine 12-lead ECG for arrhythmia

o For GSD IIIa, serial 12-lead ECG every 2 years

o More detailed rhythm analysis if any symptoms

- Repeat echocardiograms and ECGs more frequently in patients with significant ventricular hypertrophy and/or clinical symptoms

in liver. Additional protein may also offset excessive glycogen storage.

Because gluconeogenesis is intact in GSD III, sucrose, fructose, and lactose are not restricted as they are for individuals with GSD I. However, simple sugars are discouraged in favor of a diet that is higher in complex carbohydrates and protein and to reduce glycogen storage. In general, the dietary recommendations for fat follow the usual guidelines for children. The use of medium chain triglycerides (MCTs) in GSD III as an alternative source of energy and its effect on triglyceride levels warrants further investigation. There are reports of an increase in triglycerides levels with MCTs. ${ }^{83,84}$

Reduced bone mineral density has been reported in GSD III. ${ }^{88}$ Muscle, metabolic, and dietary consequences may contribute to this bone abnormality. Therefore, calcium and vitamin $\mathrm{D}$ intake must be assessed as part of the overall nutrition evaluation. Periodic laboratory evaluation of these levels may also be beneficial. Because all food groups are allowed on the diet for GSD IIIa and IIIb, vitamin and mineral supplements are only prescribed based on individual need.

CS can be introduced early; however, in infants aged younger than 12 months, CS may not be tolerated as the necessary digestive enzyme, amylase, may not be fully functional before this age. Inability to digest CS causes gas, bloating, and diarrhea. A gradual introduction of CS may help reduce some of these side effects. In some instances, pancrelipase has been used with CS to aid digestion and lessen side effects. Pancrelipase is a combination of three enzymes (proteins): lipase, protease, and amylase. These enzymes are normally produced by the pancreas and are important in the digestion of fats, proteins, and sugars. In many cases, the CS requirements in GSD III may be less than the amounts required for preventing hypoglycemia in GSD I. For these two reasons, we recommend starting with a lower dose of CS and increase it as needed, rather than treating the child with too much CS. Both dietary overtreatment and undertreatment can be problematic in GSD III. These two issues will be discussed in a later section.

One gram of CS per kilogram of body weight may be sufficient to maintain normal levels of BG for 4 hours or longer in GSD III. Initially, BG must be monitored hourly to determine if the dose of CS is adequate. Once the CS dose has been established, the frequency of BG monitoring is decreased. BG should be monitored during illness, when changes are made to the diet or schedule, to establish exercise routines, and ran- domly to detect asymptomatic hypoglycemia. In some cases of GSD IIIa or IIIb, hypoglycemia may be as severe as in GSD I and may require similar amounts of CS. In these cases, $1.6 \mathrm{~g}$ $\mathrm{CS} / \mathrm{kg}$ body weight may be needed every 4 hours for an infant or young child, and 1.7-2.5 g CS/kg body weight may be prescribed every 6 hours for an older child. For measuring purposes, one packed, level tablespoon of Argo brand CS weighs $\sim 8 \mathrm{~g}$ (Summit, IL). Repeated reports from individuals with GSD III indicate Argo brand (www.argostarch.com) CS is preferred for its taste and palatability, stability, and effectiveness. CS can be mixed in any beverage; preferably, the CS should be mixed in milk or added to yogurt to provide a source of protein and fat. In many cases, if the CS is not maintaining the child's BG at desirable levels adding more protein instead of more CS may correct the problem. ${ }^{87}$ Whey protein is recommended if protein supplements are required to increase the dietary protein. ${ }^{84}$

In severe cases, especially in infancy, when it is hard to maintain normal BG levels, continuous overnight enteral feedings may be required. The type of formula chosen for the overnight enteral feeds in GSD III does not need to be sucrose, fructose, or galactose free (as it would for the treatment of GSD I). A child older than the age of 1 year who still requires overnight enteral feedings may benefit from a higher protein formula such as those used for the treatment of diabetes. It is imperative that the child eats or takes CS as soon as the feeding pump is turned off to avoid developing hypoglycemia.

As mentioned above, providing too much CS can be problematic. ${ }^{89}$ The goal with CS formula, meals, and snacks is to give small, frequent, consistent amounts of carbohydrates to achieve a more sustained normal level of BG. Providing too much CS, too much formula, or excessively large meals can lead to excess glycogen storage in the liver and muscle and also to insulin resistance. In general, overtreating can also lead to excess weight gain, which negatively impacts the child in many ways, both psychologically and medically.

There is also a concern about undertreatment in GSD III. Some children, as well as adults, with GSD III are unable to feel the symptoms of hypoglycemia. Therefore, without randomly checking BG levels, they would not know if their diet and/or CS schedule were maintaining their BG levels in the normal range of $70-140 \mathrm{mg} / \mathrm{dL}$. Hyperketosis has been reported in patients with GSD III. It is possible that in the setting of moderate to large ketosis in GSD III as a result of increased fatty acid oxidation and upregulated neoglucogenesis, ${ }^{41} \mathrm{BG}$ levels may be 
normal. The role of ketone monitoring in this setting as a marker of metabolic control requires further systematic investigation. Monitoring of BG should be over a 1- to 2-day period periodically and especially during times of growth, or intercurrent illness. The ideal times to monitor the BG depend on the individual's schedule, but in general, BG should be checked before meals, before doses of CS, before bed, and first thing in the morning. As noted above, any time there is a change in schedule, such as with a new school year, starting dance lessons, or adding after-school sports, BG monitoring is imperative. Based on the BG results, the schedule may need to be revised by adjusting the amount of protein and/or CS and/or altering meals and snacks.

Long-term monitoring of growth is important. Tracking height-for-age, weight-for-age, weight-for-height, body mass index, and head circumference for age on standard growth charts allows any change in trends to be detected. If a change in growth parameters is noted and does not appear related to inadequate nutritional intake, then the patient should be referred to either an endocrinologist or gastroenterologist, depending on the available evidence regarding the changes in growth. Growth hormone therapy has been associated with adenoma growth and complications in GSD I, and use in any individual with GSD must be only when there is a documented growth hormone deficiency. In such a situation, the individual should be monitored closely for the appearance or increased size of adenomas and also for hypertriglyceridemia.

As with all metabolic disorders, other important issues related to feeding should not be overlooked. These include psychosocial issues and exercise. All children have a need for structure and guidance with their diet, but this is especially true for children with special diets. Early establishment of healthy dietary habits consistent with GSD III guidelines will improve the likelihood of long-term dietary compliance. Teaching children about their GSD III diet and its importance in ways that are age appropriate will help them gain independence and take ownership of their dietary needs as they grow older. When consistently providing this structure, it is also important to maintain as much normalcy about the diet as possible, so that the child does not feel isolated or adopt a negative view of the diet. Choices within the framework of the diet will allow the children to feel that they have some control. Offering more choices in other areas of their life will also give the child a sense of control.

Exercise is especially important for individuals with GSD IIIa. Manifestations of GSD IIIa, including myopathy, low bone mineral density, and hypoglycemia, are impacted by exercise and diet. Exercise in GSD IIIa is covered more thoroughly in the sections on Exercise and Physical therapy.

\section{Adults with GSD IIIa and IIIb}

The emphasis of the diet for the adult with GSD IIIa is on a higher percentage of protein. Carbohydrates may be limited, but preference should be given to complex carbohydrates, as opposed to simple sugars. Again, there are no diet restrictions with regards to specific types of sugars. Simple sugars should be avoided as they result in sudden rise and fall of BG. Recommendations for nutrient distribution vary from $20 \%$ to $30 \%$ protein, $35 \%$ to $55 \%$ carbohydrates, and $20 \%$ to $35 \%$ fat. However, most of these recommendations refer to infants and children. There are two case reports regarding the use of a high protein diet in adults with GSD IIIa. Dagli et al. outlined the course of a patient who was followed up for more than 2 decades. In infancy, $\sim 20 \%$ calories was from protein. As a teenager, he developed severe cardiomyopathy, and the amount of protein was increased to $20-25 \%$ of total calories. By age 22 years, the protein was increased to $30 \%$ of total calories, and CS was decreased to just enough to maintain normal glycemia. A dramatic improvement in his cardiomyopathy was observed, suggesting that a high protein diet without overtreating with CS can reverse and possibly prevent cardiomyopathy. ${ }^{90}$

For the adult with GSD IIIb, there is no special dietary treatment. The potential for hypoglycemia with severe stress still exits, but in general, a regular, well-balanced diet is sufficient.

\section{HEPATIC AND HEPATIC TRANSPLANT}

\section{Pathophysiology}

The liver is involved in a variety of ways in GSD III. Hepatomegaly occurs in childhood, and ALT and AST are typically elevated, consistent with hepatocellular injury. Serum activities of AST and ALT are markedly elevated in the first decade of life but tend to decrease significantly thereafter. ${ }^{74}$ Elevations of AST and ALT may also represent muscle involvement, especially in individuals with an elevated CK. Liver histology demonstrates distension of hepatocytes by glycogen and periportal septal fibrosis early in the disease process, perhaps related to the accumulation of abnormally short-branched glycogen. ${ }^{91}$ Other common histologic abnormalities are: steatosis, hepatocyte ballooning, and eventually, both centrilobular and portal-based fibrosis.

Liver disease is reported as improving with age; however, as the life expectancy of individuals with GSD III improves, the long-term hepatic manifestations of the disease are being better recognized. There are several publications of patients with cirrho$\operatorname{sis}^{18}$ and some who progressed to ESLD. ${ }^{17,20}$ The true prevalence of cirrhosis in this population is not known as liver biopsy is performed uncommonly. The estimated prevalence of cirrhosis among individuals with GSD III is based chiefly on results of laboratory testing, e.g., prolongation of the prothrombin time, low serum albumin concentration, and imaging appearances (a nodular hepatic contour and manifestations of portal venous hypertension such as splenomegaly). It is not known whether glycogen deposition and accompanying fibrosis is greater in individuals with type IIIa or IIIb disease since there are reports of liver cirrhosis in both.

There are also reports of hepatic adenoma formation and/or HCC in individuals with GSD III. ${ }^{17,19,92-93}$ In contrast to individuals with GSD I, adenomas are typically less numerous and smaller in size in GSD III. In a study of 16 patients with GSD III (age range 14-24 years), 4 developed adenomas (age range $10-19.5$ years, mean 14 years), whereas in another study, 2 of 45 patients (age range 20 months to 67 years) had hepatic adenomas. ${ }^{17,18}$ Currently, there is no biomarker that is predictive of HCC transformation in GSD III. Alpha fetoprotein and chorionic embryonic antigen levels remain normal and do not predict the presence of hepatocellular adenomas or malignant transformation. ${ }^{18,19,92}$

\section{Clinical and imaging studies}

Although the histologic abnormalities in individuals with GSD III may be striking, the only detectable biochemical abnormality for many years is elevation of the serum AST and ALT concentrations. The levels are typically between two to three times the upper limit of the normal range and are accompanied by normal synthetic function: serum albumin, PT, and bilirubin concentrations. Other potential causes of elevated aminotransferase concentrations among adults should be taken into account on the basis of risk profile-family history of chronic liver disease, identifiable risk factors for exposure to hepatitis B 


\section{GASTROINTESTINAL/NUTRITION RECOMMENDATIONS}

- A metabolic dietitian should be consulted

- In infants and children:

- Small, frequent feedings (including complex carbohydrates and protein, avoiding simple sugars) and avoidance of fasting

o Introduction of CS as early as first year of life if hypoglycemia is present

o Bedtime snack, CS, and/or continuous enteral feedings may be needed for the overnight fast

- In adolescents and adults:

o High protein ( $25 \%$ of total calories), low complex carbohydrates ( $<50 \%$ of total calories), avoidance of simple sugars, and avoidance of fasting, most importantly for those with GSD IIIa o Bedtime snack (low-fat milk with protein powder) or a high protein formula for overnight enteral feeding may be of benefit to those with myopathy

o Dietary restriction is transitioned to a regular well-balanced diet in GSD-IIIb

and/or C virus infection (body piercing, sexual promiscuity, receipt of blood or blood products before 1992, and nasal or intravenous drug use), relevant prescription drug exposure, personal or family history of autoimmune disease, and predisposing conditions for nonalcoholic fatty liver disease, e.g., systemic hypertension and type 2 diabetes mellitus.

To what extent the increase in transaminase concentrations is associated with symptoms such as fatigue is less clear. The individual's clinical course, particularly if myopathy is present, will be dictated by those features rather than by the effects of liver injury.

Liver imaging is routinely performed in individuals with GSD III. In younger children ( $<18$ years), liver ultrasound can be performed every 12 to 24 months. With increasing age, computed tomography or magnetic resonance imaging scanning using intravenous contrast should be considered to look for evidence of liver cirrhosis (nodular hepatic contour and manifestations of portal venous hypertension such as splenomegaly), presence of adenomas, and evidence of HCC.

\section{Liver transplantation and organ allocation}

Although individuals with GSD III may develop histologic evidence of cirrhosis, so long as their synthetic function remains normal or well preserved, liver transplantation (LT) is not necessary. In the United States, and increasingly in other countries, priority for LT is governed by the individual's model for ESLD (MELD) score. This score is calculated using a logarithmic assessment of three objective and reproducible variables, namely total serum bilirubin and creatinine concentrations, and the international normalized ratio. The score may range from as low as 6 to a high capped at 40. In contrast to the Child's score, which formed the basis of assessment of disease severity and, therefore, organ allocation until 2002, the MELD score represents a continuous assessment of liver disease severity. ${ }^{94}$

The primary function of the MELD score is to estimate an individual's mortality risk from liver disease and its complications during the next 90 days: the higher the score the greater the risk of death. A MELD score of $15-17$ is significant in that this is the point at which the mortality risk associated with liver disease and its complications is equivalent to the 1-year mortality associated with complications arising from LT. ${ }^{95}$ Since the inception of MELD score as the basis for deceased donor organ allocation, patients with HCC have been granted additional priority.

It has been suggested that individuals with GSD III and advanced liver disease should be considered for liver transplant. ${ }^{17}$ In GSD III, because the hepatic abnormalities are the result of a single gene, cell autonomous defect, there is no possibility of recurrence of primary liver disease within the transplanted allograft. LT does not correct the skeletal or cardiac manifestations of GSD III. ${ }^{96,97}$ Few individuals have undergone LT for GSD III. ${ }^{96,97}$

As individuals with GSD III continue to have a better quality of life and live longer, it is possible that the incidence both of ESLD and HCC will also increase, thereby resulting in greater demands on liver transplant services.

\section{MUSCULOSKELETAL/FUNCTIONAL/ REHABILITATION}

\section{Neuromuscular and musculoskeletal}

\section{The clinical spectrum}

Clinical manifestations in GSD III, as described earlier, are heterogeneous, ranging from asymptomatic to significant prox- 


\section{HEPATIC RECOMMENDATIONS}

- Laboratory testing to include serum AST, ALT, PT, bilirubin, and albumin every 6 months to yearly to monitor extent of hepatic damage and to delineate if there is progression of liver cirrhosis to end-stage liver failure

- Alpha feto protein and Chorionic embryonic antigen levels do not predict the presence of hepatocellular adenomas or malignant transformation

- Abdominal Ultrasound is reasonable in a pediatric population. Abdominal imaging should be performed at baseline and then every 12-24 months

- Abdominal Computed tomography/Magnetic resonance imaging with contrast should be performed in older patients every 6-12 months based on laboratory and clinical findings

- Monitoring of the patient's MELD is used to assess liver disease severity

imal and distal weakness and atrophy. In childhood, muscle symptoms are reported as usually absent or mild. In a series of 16 patients aged 3-22 years, detailed neuromuscular evaluation revealed one patient with severe weakness, four with slight involvement, and 11 who were asymptomatic or minimally affected. ${ }^{98}$ However, subtle motor delay in children may be more widespread than previously identified, and a recent report described that $80 \%$ of children with GSD IIIa had average gross motor function below the 25 th percentile for age. ${ }^{99}$ The most common neuromuscular manifestations of GSD IIIa in children are hypotonia and/or mild nonprogressive weakness, which may mimic a congenital myopathy. Gross motor symptoms presenting in early childhood may improve or resolve somewhat with the potential for reemergence of proximal and distal weakness in adult, exacerbated by distal atrophy suggesting underlying neuropathy. ${ }^{49}$ Musculoskeletal features may include hypermobility at individual joints, with hyperextension at knees and elbows, and alignment characterized by an anterior pelvic tilt and mild lumbar lordosis, slightly increased width of base of support, genu valgum and recurvatum, hindfoot valgus, and forefoot varus. Anterior pelvic tilt and increased width of base of support may be related to postures assumed to accommodate increased abdominal girth from hepatomegaly and may lead to biomechanical disadvantage in the use of abdominal muscles and hip extensors and abductors. Increased abdominal girth when young may alter postural development. Weakness, whether primary and related to debrancher enzyme deficiency or secondary to altered biomechanics or both, seems to affect trunk and proximal muscles (abdominal muscles, hip extensors, and abductors) and distal muscles, with decreased grip strength and decreased ability to jump and hop. ${ }^{99}$

Significant weakness attributable to debrancher deficiency most often is recognized in adult life. ${ }^{21,53,58}$ In the review by Cornelio et al., ${ }^{21}$ weakness emerged in the $3 \mathrm{rd}$ or 4 th decade of life in $70 \%$ of patients with debrancher myopathy, and the course was generally slowly progressive and not debilitating. ${ }^{21,58}$ The distribution of weakness and associated features of the myopathy are highly variable. Individuals may have symmetrical, predominantly proximal or more generalized weakness, occasionally in association with hypertrophy/pseudohypertrophy of some muscles.49,101 Another characteristic manifestation is distal weakness and atrophy suggesting underlying neuropathy. Although these cases may be termed distal myopathy, peripheral neuropathy due to debrancher deficiency may contribute to this pattern of weakness. It appears that these findings may become more evident with increasing age and that the median nerve may be preferentially involved. Consistent with this view is the finding of glycogen accumulation in peripheral nerves, abnormal nerve conduction velocities, and "neuropathic" features by EMG. Clinical heterogeneity is paralleled by genetic heterogeneity, 28,55 and even among individuals with the same mutation, the range of muscle symptoms has varied from minimal to severe for reasons that are unclear. ${ }^{101}$ The responsible variables have yet to be identified.

\section{Implications for muscle energy metabolism and exercise}

Muscle glycogen is a crucial fuel for anaerobic metabolism to support maximal effort and is broken down by myophosphorylase and muscle debranching enzyme. Despite the fact that muscle glycogen is crucial for normal muscle energy metabolism, dynamic symptoms of exercise intolerance are not recognized in GSD III. ${ }^{49}$ Unlike GSD V and VII, and distal glycolytic defects, exertional muscle contractures or recurrent rhabdomyolysis are not features of this disorder. ${ }^{49,58}$ The fact that similar symptoms have not been described in GSD IIIa suggests that glycogen branches accessible to myophosphorylase (enzyme deficient in GSD V) provide sufficient anaerobic glycogenolysis to be protective.

In addition to anaerobic metabolism, muscle glycogen is also necessary for normal muscle oxidative metabolism. It provides a substrate for oxidative phosphorylation in the transition from rest to exercise. In fact, glycogen is a critical oxidative substrate to support maximal rates of oxidative phosphorylation. ${ }^{103}$ In healthy humans, muscle glycogen depletion results in muscle fatigue and a substantial drop in aerobic power. Limited aerobic capacity or reduced endurance have not been identified as characteristic features of GSD IIIa. This may relate to a protective effect of retained capacity to metabolize glucosyl residues accessible to myophosphorylase. It may also be attributable to a protective effect of weakness that limits exercise or to a lack of appropriate testing of affected individuals. Furthermore, impaired aerobic capacity or reduced endurance is notoriously difficult to assess without quantitative exercise testing and ap- 
propriate controls. ${ }^{103}$ Limited degradation of muscle glycogen in GSD IIIa would be expected to deplete available glycogen more rapidly and shorten the period of exercise necessary to produce muscle fatigue. The associated restriction in hepatic glucose production in GSD III, by limiting the normal increase in muscle utilization of BG during sustained exercise, also would be expected to limit sustained exercise and could potentially provoke hypoglycemia. The fact that neither have been described may relate to increased abundance of alternative oxidative fuels (free fatty acids and ketone bodies), to enhanced capacity for gluconeogenesis and fatty acid oxidation, ${ }^{41}$ or to a lack of appropriate and rigorous testing.

A lack of information limits the ability to provide firm recommendations regarding regular exercise in GSD III. Nevertheless, the benefits of exercise training in muscle phosphorylase deficiency (GSD V) suggest that aerobic conditioning may be beneficial also in GSD III. ${ }^{104}$ Similarly, recommendations regarding resistance exercise or strength training await appropriate studies. The vulnerability of other disorders of muscle glycogenolysis and glycolysis to injury triggered by maximal effort suggests that such exercise be approached with caution in GSD III.

\section{Physical therapy}

Musculoskeletal assessment is recommended with respect to potential alterations in alignment described earlier (hypermobility, increased width of base of support, anterior pelvic tilt, genu valgum and recurvatum, hindfoot valgus, and forefoot varus). Intervention with custom-molded foot orthoses may improve distal alignment at feet and ankles and secondarily decrease genu valgum, leading to improved weight-bearing alignment for protection of the musculoskeletal system over time. Taller orthotic intervention with ankle foot orthoses may be recommended for more severe malalignment, instability, or distal weakness in adults. Direct and functional assessment of strength and endurance is recommended for monitoring status over time and guiding individualized exercise programs as described above. Standardized gross and fine motor testing in children is recommended to assess function relative to age-level peers, to identify specific individual areas of impairment and decreased function, and to optimize participation. Functional adaptation and appropriate provision of adaptive equipment may address fine motor issues compromised by distal weakness (cutting, writing, keyboard use, and opening jars). This may include adaptations for participation, such as driving modification if grasp or upper extremity strength and function are compromised or if lower extremity involvement necessitates use of hand controls, and may include mobility devices if needed because of decreased strength or endurance. Avoidance of contact sports in the presence of hepatomegaly may be advised in children. Aggressive upper extremity weight-bearing activities (such as cartwheels) and/or activities involving potential joint distraction in suspension activities (such as climbing trees and monkey bars) should be avoided in children with hypermobility/instability at elbows coupled with decreased strength. Median nerve damage may occur at the wrist in adults because of compression from glycogen deposition in the nerve within the limited space of the carpal tunnel. ${ }^{28}$ Wrist splints may be recommended when sleeping to avoid excessive wrist flexion, which could exacerbate compression within the carpal tunnel. Appropriate precautions in individuals with cardiac involvement have been described in the Cardiology section.

\section{GENERAL MEDICAL CARE}

General medical care should be individualized as disease manifestations vary. During childhood, routine immunizations should be given on the recommended schedule. Any immunizations that may prevent illness (such as influenza leading to hypoglycemia) should be offered, because these may avoid an illness and the risk of hypoglycemia. Hepatitis B immunizations should be given. Hepatitis $\mathrm{C}$ status should be monitored in individuals with risk factors for hepatitis C. Hepatitis B or C infection may potentiate the risk for liver tumors in individuals with GSD III. ${ }^{18}$

Beta-blockade is often prescribed in individuals with hypertrophic cardiomyopathy with ventricular outflow tract obstruction. Beta-blockers should be used with great caution in individuals with GSD III because of their potential to mask the symptoms of hypoglycemia, and other medications should be considered before using a beta-blocker.

There is little available information regarding the use of over-the-counter medications and concomitant hypoglycemia in individuals with GSD III. Although there are no reports in the literature of drugs precipitating hypoglycemia in children with GSD III, drugs known to cause hypoglycemia should be avoided. The most important agents causing hypoglycemia are insulin and insulin secretogogues (the sulfonylureas). Parents of children with hypoglycemia should be educated on the importance of monitoring during intercurrent illnesses that may involve prolonged fasting. Medic-Alert bracelets and emergency letters from the managing physician are helpful and should be provided. Hypoglycemic events in adults with GSD III are relatively uncommon; however, caution should be used with drugs causing potential hypoglycemia, particularly in cases of impaired liver function. Alcohol may predispose individuals to hypoglycemia. ${ }^{105}$ There is at least one report of concomitant diabetes in an adult with GSD III who was successfully treated with an oral alpha-glucosidase inhibitor. ${ }^{106}$ For patients with GSD IIIa and hyperlipidemia, statins are relatively contraindicated, given their potential to unmask or worsen existing myopathy.

\section{GYNECOLOGICAL/OBSTETRICAL CARE}

Caution should be used when prescribing hormonal birth control; estrogen is known to contribute to both benign and malignant hepatocellular tumors. ${ }^{107}$ Given the risk of adenomas in this group, estrogen should be avoided when possible. ${ }^{108}$ Progestin-only contraceptives do not pose the same risk and may be considered; however, there are other challenges such as risk for reduced bone mineral density, which needs to be monitored. ${ }^{109}$

Females with GSD III are known to have polycystic ovaries from a young age, ${ }^{31}$ on rare occasions, individuals can develop hirsutism, irregular menstrual cycles, and other features of polycystic ovarian syndrome. Fertility is not thought to be reduced. There have been reports of successful pregnancies in individuals with GSD III. ${ }^{32-34,110}$

\section{Pregnancy}

Any woman with GSD III who chooses to pursue pregnancy runs some risks and requires careful follow-up by a high risk obstetrician. Ideally, individuals with GSD III will consult with their health care team and maintain optimal metabolic control before conception. The primary goal during pregnancy is to maintain normoglycemia. The appropriate diet during pregnancy is unique to each individual. For some, this may only require following a regular healthy diet, but for many, it may mean increasing snacks to include more complex carbohydrates and protein and/or adding or increasing the amount of CS. 


\section{MUSCULOSKELETAL/FUNCTIONAL/NEUROMUSCULAR REHABILITATION RECOMMENDATIONS}

Physical therapy evaluation recommended every 6 months or more frequently based on physical status, function, or need

Physical therapy assessment including

- Musculoskeletal assessment

- mobility/hypermobility/muscle extensibility

- posture and spinal alignment

- pelvic alignment

- width of base of support in standing

- genu valgus/recurvatum

- foot and ankle alignment

- elbow hyperextension

- Strength/endurance assessment

- Pain assessment

- Standardized assessment of age appropriate developmental/functional status

Assessment of exercise capacity and individualized exercise guidance as needed

Coordination with nutrition regarding monitoring and optimizing blood glucose levels for exercise and activity levels

Coordination with cardiology in the presence of cardiac involvement

Physical therapy intervention based on physical therapy assessment

Adaptive equipment may include

- orthotic intervention

- hand splints

- mobility devices

- driving modification

- devices/modifications as needed for transfers, access, activities of daily living, work, school, and participation

Neuromuscular consultation at time of diagnosis with follow -up as symptoms change

Neuromuscular assessment for patients with weakness including

- assessment for treatable causes of hand weakness (carpal tunnel syndrome)

- characterization of any peripheral neuropathy present and evaluation for contributing factors unrelated to GSD III (diabetes mellitus, demyelinating neuropathy, etc.)

Repeat EMG/nerve conduction study should be performed if signs of polyneuropathy or intrinsic hand muscle weakness develop

Orthopedic consultation as needed 


\section{GENERAL MEDICAL CARE RECOMMENDATIONS}

- Routine immunizations should be offered including hepatitis B.

- Medic-Alert bracelets and emergency letters to manage hypoglycemia

- Caution with drugs that can cause hypoglycemia

o Beta-blockers should be used with caution in patients with cardiomyopathy because of their potential to mask symptoms of hypoglycemia

- Caution with lipid-lowering drugs such as statins that can worsen or unmask myopathy

- Caution with prolonged fasting

o During surgery/anesthesia

o During periods of intercurrent illness

Hypoglycemia may be more difficult to control attributable to the accelerated starvation state of pregnancy, thus requiring a more constant and reliable route of glucose/protein administration such as continuous nasogastric feeds, CS every 4-6 hours, and central hyperalimentation. Adequate amount of protein is necessary to provide an alternate source of glucose via gluconeogenesis. It is extremely important to maintain euglycemia throughout pregnancy and to avoid upregulation of counterregulatory hormones (this would result in lipolysis and ketosis, with risk of fetal demise).

Complications of GSD III in reproductive-age women include hepatic adenomas, osteoporosis, and exacerbation of liver symptoms. Hepatic adenomas may increase in size caused by the hormonal changes of pregnancy. Radiology imaging should be performed before pregnancy and after delivery to monitor this risk. Physical therapy assessment may be helpful regarding altered biomechanics and musculoskeletal management.

Management may benefit from a planned delivery via induction in a tertiary care facility. At the time of delivery, important precautions include the use of an intravenous glucose infusion (to prevent hypoglycemia); usually, D10 is preferred. Coordination of care with a high-risk obstetrical group and the metabolic team are essential. Prior arrangements for labor, delivery, and postpartum recovery should include a dextrose infusion until the mother can resume eating and is able to maintain normoglycemia. ${ }^{32,33,110}$

\section{SURGERY/ANESTHESIA}

Children with GSD IIIa should be monitored for hypoglycemia during any surgical procedure. The duration of allowable preoperative fasting should be based on the individual's usual dietary history. If periods of 4-6 hours of fasting cannot be tolerated without hypoglycemia, intravenous glucose at a rate and concentration to maintain $\mathrm{BG}>70 \mathrm{mg} / \mathrm{dL}$ should be provided. Hepatic enlargement may impact anesthetic care because of its effect on diaphragmatic excursion. Hepatic involvement in GSD III causes elevation of hepatic enzymes with generally normal synthetic function; however, because some individuals develop progressive cirrhosis, coagulation function should be assessed before surgery. In cases of cirrhosis, anesthetic agents with known negative effects on the liver should be avoided. ${ }^{11}$ The anesthetic implications of the myopathy associated with GSD III do not appear to differ from those of other myopathies. There may be an increased sensitivity to the nondepolarizing agents. Agents such as succinylcholine should not be used in individuals with myopathy given their potential for rhabdomyolysis. Careful perioperative monitoring is recommended given the possibility of respiratory and metabolic complications during surgery and anesthesia. ${ }^{112}$

\section{CARE COORDINATION AND SUPPORT}

The Association of Glycogen Storage Disease (http://www.agsdus.org/) is an organization that provides information and support to people with GSD and their families. The Web site provides descriptions of the various types of GSD and a listserve, a mechanism for people with all forms of GSD to connect via the Internet. The AGSD also holds a medical conference each year for individuals with GSD and their families.

In the United States, the Muscular Dystrophy Association (MDA) also supports individuals with GSD III. Their publication "Metabolic Diseases of the Muscle" is available for download on the MDA Web site, www.mda.org. Because of the muscular manifestations of GSD III, certain equipment and services may be available at free or at reduced cost via a participating MDA clinic.

\section{GENETIC COUNSELING, PRENATAL DIAGNOSIS, AND SCREENING}

Similar to other inborn errors of metabolism, genetic counseling should be offered to all parents of children with GSD III and to adults affected with the condition. In counseling families with GSD III, at least a three-generation pedigree from the 


\section{GYNECOLOGICAL/OBESTRICAL RECOMMENDATIONS}

- Avoidance of estrogen as an oral contraceptive

- Maintenance of normoglycemia and avoidance of hypoglycemia and ketosis is critical throughout the pregnancy and during labor and delivery

- A planned delivery via induction and/or close to a tertiary care facility important to ensure good maternal and fetal outcome

\section{SURGERY/ANESTHESIA RECOMMENDATIONS}

- Preoperative evaluation to include hepatic enzymes and liver synthetic function to help determine appropriate anesthetic

- Recommend discussion with surgical and anesthesia team for coordinated approach and for discussion of intravenous glucose to maintain glucose $>70 \mathrm{mg} / \mathrm{dL}$

- Medications like succinylcholine that can cause rhabdomyolysis must be avoided

- Monitoring for hypoglycemia in the pre-, peri-, and postoperative period is critical

consult and or proband should be obtained. GSD III is an autosomal recessive condition. De novo mutation rates are expected to be infrequent, and parents of an affected individual are assumed to be carriers. The recurrence risk to parents who have had an affected child is $25 \%$. DNA mutation analysis is necessary for the identification of additional family members in the extended family who may be carriers. Several laboratories in the United States offer DNA diagnostic and/or prenatal diagnostic testing for GSD III (see www.genetests.org). GSD IIIa mutations are equally distributed among the large 35-exon $A G L$ gene. When screening for GSD IIIb, some laboratories may only screen for two common mutations in exon 3-c.18_19delGA (p.Gln6HisfsX20), formerly described as c.17_18delAG, and c. $16 \mathrm{C}>\mathrm{T}$ (p.Gln6X) - rather than perform full-gene sequencing. Identifying mutations for GSD IIIa requires full sequencing. Identification of carrier status in the general population is limited and not routinely offered; however, mutation analysis to further refine the risk of having a child with GSD III can be offered to those at risk (e.g., the spouse of a known carrier or spouse of an affected person).

Prenatal diagnostic testing is typically performed by mutation analysis either on cultured chorionic villus samples or amniocytes, ideally of the probands of previously identified $A G L$ mutations. When the mutations segregating in the family are known, molecular testing is the gold standard. PGD is also an option for families with GSD III if the mutations have been identified.

\section{FUTURE DIRECTIONS AND EMERGING THERAPIES}

Current therapies for GSD III continue to be symptomatic and nutrition based. Whether there is a role for compounds that provide an alternative source of energy is questionable and warrants further investigation. Certainly, there has been a surge of interest regarding the role of anaplerotic compounds as triheptanoin in patients with inborn errors of metabolism and the potential for secondary energy compromise. One adult patient with Pompe disease reportedly improved after the use of triheptanoin as an alternative fuel. ${ }^{113}$ To our knowledge, this form of therapy has not been tested in patients with GSD III. Furthermore, the role of MCT oil remains debatable until more evidence is available with regard to the effect on triglycerides. Future research is needed to design treatment strategies that may potentially prevent or suppress glycogen accumulation, provide alternative sources of energy, or target specific pathway abnormalities. The effect of diet (particularly high protein diet), exercise, and influence of hormonal changes needs long-term evaluations. Unfortunately, there is no clinical application for small molecule therapy, enzyme replacement, or gene replacement therapy in GSD III.

Several challenges remain before clinical testing of therapeutic strategies can be considered. Assessing the role of any new therapy will depend on the availability of sensitive new biomarkers that correlate with clinicopathologic findings and/or disease severity. This goal demands further characterization and understanding of the natural history of GSD III and the clinical and biochemical phenotypic changes that occur overtime with increasing age. Long-term complications of the disease are now more recognized. The extent of hepatic, cardiac, and muscle/nerve involvement need focused systematic reviews. At the same time, the role of clinical biomarkers in urine and blood of GSD III patients has been underrated. There is a need for biomarkers that correlate with disease severity to determine prognosis or efficacy of treatment. A urinary biomarker, Hex4, was shown to correlate 


\title{
GENETIC COUNSELING/PRENATAL DIAGNOSIS/SCREENING RECOMMENDATIONS
}

\author{
- Offer genetic counseling to all parents with a child with GSD III and to all adults with \\ GSD III.
}

- Determine the proband's $A G L$ mutations when feasible.

For prenatal diagnosis:

- Molecular testing is the preferred method when both mutations are known.

well with disease severity in GSD III patients with significant disease involvement compared with other traditional serum markers. ${ }^{99}$ Animal models for GSD III are needed to further understand and allow for future therapies. ${ }^{114}$ Physicians need to be aware of the signs and symptoms of this disease to make an early diagnosis and refer the patient to a metabolic specialist for further management. A multidisciplinary approach involving the metabolic team together with the primary care physician, hepatologist, neurologist, cardiologist, and physical therapist should be followed to ensure the best care and outcome for these patients.

\section{ACKNOWLEDGMENTS}

This project was supported by educational grants from the Association for Glycogen Storage Disease, US, and the American College of Medical Genetics Foundation.

We thank Salvatore DeMauro, MD, Mark Tarnopolsky, MD, $\mathrm{PhD}$, William Rhead, MD, Lane Rutledge, MD, Joseph Wolfsdorf, MD, and Yuan-Tsong Chen, $\mathrm{MD}, \mathrm{PhD}$, for their prepublication reviews of this guideline.

\section{REFERENCES}

1. Illingworth B, Cori GT. Structure of glycogens and amylopectins. III. Normal and abnormal human glycogen. $J$ Biol Chem 1952;199:653-660.

2. Forbes GB. Glycogen storage disease: report of a case with abnormal glycogen structure in liver and skeletal muscle. J Pediatr 1953;42:645653.

3. Illingworth B, Cori GT, Cori CF. Amylo-1,6-glucosidase in muscle tissue in generalized glycogen storage disease. J Biol Chem 1956;218:123-129.

4. Snappes I, Van Creveld S. Un cas d'hypoglycemie avec acetonemie chez un enfant. Bull Mem Soc Med Hop 1928;52:1315.

5. Van Creveld S, Huijing F. Differential diagnosis of the type of glycogen disease in two adult patients with long history of glycogenosis. Metabolism 1964;13:191-194.

6. Huijing F. Amylo-1,6-glucosidase activity in normal leucocytes and in leucocytes of patients with glycogen-storage disease. Clin Chim Acta 1964;9:269-272

7. Yang BZ, Ding JH, Enghild JJ, Bao Y, Chen YT. Molecular cloning and nucleotide sequence of cDNA encoding human muscle glycogen debranching enzyme. J Biol Chem 1992;267:9294-9299.

8. Bao Y, Dawson TL Jr, Chen YT. Human glycogen debranching enzyme gene (AGL): complete structural organization and characterization of the $5^{\prime}$ flanking region. Genomics 1996;38:155-165.

9. Bao Y, Yang BZ, Dawson TL Jr, Chen YT. Isolation and nucleotide sequence of human liver glycogen debranching enzyme mRNA: identification of multiple tissue-specific isoforms. Gene 1997;197:389-398.

10. Howell R, Williams J. The glycogen storage diseases. In: Stanbury JB, Fredrickson DS, Goldstein JL, Brown MS, editors. The metabolic basis of inherited disease, 5th ed. New York: McGraw-Hill; 1983:141.

11. Van Hoof F, Hers HG. The subgroups of type 3 glycogenosis. Eur J Biochem 1967;2:265-270.

12. Angelini C, Martinuzzi A, Vergani L. Glycogen storage diseases of muscle.
In: Lane R, editor. Handbook of muscle diseases. New York, NY: Marcel Dekker; 1996:407.

13. Ding JH, de Barsy T, Brown BI, Coleman RA, Chen YT. Immunoblot analyses of glycogen debranching enzyme in different subtypes of glycogen storage disease type III. J Pediatr 1990;116:95-100.

14. Sugie H, Fukuda T, Ito M, Sugie Y, Kojoh T, Nonaka I. Novel exon 11 skipping mutation in a patient with glycogen storage disease type IIId. $J$ Inherit Metab Dis 2001;24:535-545.

15. Lee P, Burch M, Leonard JV. Plasma creatine kinase and cardiomyopathy in glycogen storage disease type III. J Inherit Metab Dis 1995;18:751-752.

16. Coleman RA, Winter HS, Wolf B, Chen YT, Glycogen debranching enzyme deficiency: long-term study of serum enzyme activities and clinical features. J Inherit Metab Dis 1992;15:869-881.

17. Labrune P, Trioche P, Duvaltier I, Chevalier P, Odievre M. Hepatocellular adenomas in glycogen storage disease type I and III: a series of 43 patients and review of the literature. J Pediatr Gastroenterol Nutr 1997;24:276279.

18. Demo E, Frush D, Gottfried M, Koepke J, Boney A, Bali D, et al. Glycogen storage disease type III-hepatocellular carcinoma a long-term complication? J Hepatol 2007;46:492-498.

19. Siciliano M, De Candia E, Ballarin S, et al. Hepatocellular carcinoma complicating liver cirrhosis in type IIIa glycogen storage disease. J Clin Gastroenterol 2000;31:80-82.

20. Matern D, Starzl TE, Arnaout W, et al. Liver transplantation for glycogen storage disease types I, III, and IV. Eur J Pediatr 1999;158(suppl 2):S43S48.

21. Cornelio F, Bresolin N, Singer PA, DiMauro S, Rowland LP. Clinical varieties of neuromuscular disease in debrancher deficiency. Arch Neurol 1984;41:1027-1032.

22. Hobson-Webb LD, Austin SL, Bali D, Kishnani PS. The electrodiagnostic characteristics of Glycogen Storage Disease Type III. Genet Med 2010;12:440-445.

23. Kotb MA, Abdallah HK, Kotb A. Liver glycogenoses: are they a possible cause of polyneuropathy? A cross-sectional study. J Trop Pediatr 2004; 50:196-202.

24. Labrune P, Huguet P, Odievre M. Cardiomyopathy in glycogen-storage disease type III: clinical and echographic study of 18 patients. Pediatr Cardiol 1991;12:161-163.

25. Miller CG, Alleyne GA, Brooks SE. Gross cardiac involvement in glycogen storage disease type 3. Br Heart $J$ 1972;34:862-864.

26. Moses SW, Wanderman KL, Myroz A, Frydman M. Cardiac involvement in glycogen storage disease type III. Eur J Pediatrics 1989;148:764-766.

27. Lee PJ, Deanfield JE, Burch M, Baig K, McKenna WJ, Leonard JV. Comparison of the functional significance of left ventricular hypertrophy in hypertrophic cardiomyopathy and glycogenosis type III. Am $J$ Cardiol 1997;79:834-838.

28. Shen J, Bao Y, Chen YT. A nonsense mutation due to a single base insertion in the 3 '-coding region of glycogen debranching enzyme gene associated with a severe phenotype in a patient with glycogen storage disease type IIIa. Hum Mutat 1997;9:37-40.

29. Vertilus SM, Austin SL, Foster KS, et al. Echocardiographic manifestations of Glycogen Storage Disease III: increase in wall thickness and left ventricular mass over time. Genet Med 2010;12:413-423.

30. Cabrera-Abreu J, Crabtree NJ, Elias E, Fraser W, Cramb R, Alger S. Bone mineral density and markers of bone turnover in patients with glycogen storage disease types I, III and IX. J Inherit Metab Dis 2004;27:1-9.

31. Lee PJ, Patel A, Hindmarsh PC, Mowat AP, Leonard JV. The prevalence of polycystic ovaries in the hepatic glycogen storage diseases: its associ- 
ation with hyperinsulinism. Clin Endocrinol (Oxf) 1995;42:601-606.

32. Confino E, Pauzner D, Lidor A, Yedwab G, David M. Pregnancy associated with amylo-1,6-glucosidase deficiency (Forbe's disease). Case report. $\mathrm{Br} J$ Obstet Gynaecol 1984;91:494-497.

33. Bhatti S, Parry E. Successful pregnancy in a woman with glycogen storage disease type III. Aust N Z J Obstet Gynaecol 2006;46:168-169.

34. Mendoza A, Fisher NC, Duckett J, et al. Successful pregnancy in a patient with type III glycogen storage disease managed with cornstarch supplements. Br J Obstet Gynaecol 1998;105:677-680.

35. Elpeleg ON. The molecular background of glycogen metabolism disorders. $J$ Pediatr Endocrinol Metab 1999;12:363-379.

36. Lucchiari S, Fogh I, Prelle A, et al. Clinical and genetic variability of glycogen storage disease type IIIa: seven novel AGL gene mutations in the Mediterranean area. Am J Med Genet 2002;109:183-190.

37. Clayton PT. Diagnosis of inherited disorders of liver metabolism. J Inherit Metab Dis 2003;26:135-146.

38. Wolfsdorf JI, Holm IA, Weinstein DA. Glycogen storage diseases. Phenotypic, genetic, and biochemical characteristics, and therapy. Endocrinol Metab Clin North Am 1999;28:801-823.

39. Lee P, Mather S, Owens C, Leonard J, Dicks-Mireaux C. Hepatic ultrasound findings in the glycogen storage diseases. Br J Radiol 1994;67:10621066.

40. Binkiewicz A, Senior B. Decreased ketogenesis in von Gierke's disease (type I glycogenosis). J Pediatr 1973;83:973-978.

41. Fernandes J, Pikaar NA. Ketosis in hepatic glycogenosis. Arch Dis Child 1972;47:41-46.

42. Fischer KF, Lees JA, Newman JH. Hypoglycemia in hospitalized patients. Causes and outcomes. N Engl J Med 1986;315:1245-1250.

43. Wolf AD, Lavine JE. Hepatomegaly in neonates and children. Pediatr Rev 2000;21:303-310

44. Moses SW, Parvari R. The variable presentations of glycogen storage disease type IV: a review of clinical, enzymatic and molecular studies. Curr Mol Med 2002;2:177-188.

45. Mellies U, Lofaso F. Pompe disease: a neuromuscular disease with respiratory muscle involvement. Respir Med 2009;103:477-484.

46. Servidei S, Metlay LA, Chodosh J, DiMauro S. Fatal infantile cardiopathy caused by phosphorylase b kinase deficiency. $J$ Pediatr 1988;113(1 Pt 1): $82-85$.

47. Charpentier C, Saudubray J. Clinical phenotypes: diagnosis/algorithms. In: Valle D, Beaudet A, Vogelstein B, Kinzler K, Antonarakis S, Ballabio A, editors. Scriver's online metabolic \& molecular bases of inherited disease. New York, NY: McGraw-Hill; 2009.

48. Ugawa Y, Inoue K, Takemura T, Iwamasa T. Accumulation of glycogen in sural nerve axons in adult-onset type III glycogenosis. Ann Neurol 1986; 19:294-297.

49. Kiechl S, Kohlendorfer U, Thaler C, et al. Different clinical aspects of debrancher deficiency myopathy. J Neurol Neurosurg Psychiatry 1999;67:364-368.

50. Mineo I, Kono N, Hara N, et al. Myogenic hyperuricemia. A common pathophysiologic feature of glycogenosis types III, V, and VII. $N$ Engl J Med 1987;317:75-80.

51. Chen YT, Kishnani PS, Koeberl DD. Glycogen storage diseases. In: Valle D, Beaudet A, Vogelstein B, Kinzler K, Antonarakis S, Ballabio A, editors. Scriver's online metabolic \& molecular bases of inherited disease. New York, NY: McGraw-Hill; 2009

52. McAdams AJ, Hug G, Bove KE. Glycogen storage disease, types I to X: criteria for morphologic diagnosis. Hum Pathol 1974;5:463-487.

53. DiMauro S, Hartwig GB, Hays A, et al. Debrancher deficiency: neuromuscular disorder in 5 adults. Ann Neurol 1979;5:422- 436.

54. Miranda AF, DiMauro S, Antler A, Stern LZ, Rowland LP. Glycogen debrancher deficiency is reproduced in muscle culture. Ann Neurol 1981; 9:283-288.

55. Shen JJ, Chen YT. Molecular characterization of glycogen storage disease type III. Curr Mol Med 2002;2:167-175.

56. Maire I, Baussan C, Moatti N, Mathieu M, Lemonnier A. Biochemical diagnosis of hepatic glycogen storage diseases: 20 years French experience. Clin Biochem 1991;24:169-178.

57. Shaiu WL, Kishnani PS, Shen J, Liu HM, Chen YT. Genotype-phenotype correlation in two frequent mutations and mutation update in type III glycogen storage disease. Mol Genet Metab 2000;69:16-23.

58. DiMauro S, Tsujino S. Nonlysosomal glycogenoses. In: Engel AG, FranziniArmstrong C, editors. Myology. New York, NY: McGraw Hill; 1994: 1554-1579.

59. Maire I, Mathieu M. Possible prenatal diagnosis of type III glycogenosis. J Inherit Metab Dis 1986;9:89-91

60. Shin YS. Diagnosis of glycogen storage disease. $J$ Inherit Metab Dis 1990;13:419-434.

61. Besley GT, Cohen PT, Faed MJ, Wolstenholme J. Amylo-1,6-glucosidase activity in cultured cells: a deficiency in type III glycogenosis with prenatal studies. Prenat Diagn 1983;3:13-19.

62. Shin YS, Ungar R, Rieth M, Endres W. A simple assay for amylo-1,6glucosidase to detect heterozygotes for glycogenosis type III in erythrocytes. Clin Chem 1984;30:1717-1718.
63. Shin YS, Rieth M, Tausenfreund J, Endres W. First trimester diagnosis of glycogen storage disease type II and type III. J Inherit Metab Dis 1989; 12(suppl 2):289-291.

64. Yang BZ, Ding JH, Brown BI, Chen YT. Definitive prenatal diagnosis for type III glycogen storage disease. Am J Hum Genet 1990;47:735-739.

65. Goldstein JL, Austin SL, Boyette K, et al. Molecular analysis of the $A G L$ gene: identification of 25 novel mutations and evidence of genetic heterogeneity in patients with Glycogen Storage Disease Type III. Genet Med 2010;12:424-430.

66. Shen J, Bao Y, Liu HM, Lee P, Leonard JV, Chen YT. Mutations in exon 3 of the glycogen debranching enzyme gene are associated with glycogen storage disease type III that is differentially expressed in liver and muscle. J Clin Invest 1996;98:352-357.

67. Okubo M, Horinishi A, Nakamura N, et al. A novel point mutation in an acceptor splice site of intron 32 (IVS32 A-12-_G) but no exon 3 mutations in the glycogen debranching enzyme gene in a homozygous patient with glycogen storage disease type IIIb. Hum Genet 1998;102:1-5.

68. Cheng A, Zhang M, Okubo M, Omichi K, Saltiel AR. Distinct mutations in the glycogen debranching enzyme found in glycogen storage disease type III lead to impairment in diverse cellular functions. Hum $\mathrm{Mol}$ Genet 2009;18:2045-2052.

69. Lucchiari S, Santoro D, Pagliarani S, Comi GP. Clinical, biochemical and genetic features of glycogen debranching enzyme deficiency. Acta Myol 2007;26:72-74

70. Pearson CM. Glycogen metabolism and storage diseases of types III, IV and V. Am J Clin Pathol 1968;50:29-43.

71. Olson LJ, Reeder GS, Noller KL, Edwards WD, Howell RR, Michels VV. Cardiac involvement in glycogen storage disease III: morphologic and biochemical characterization with endomyocardial biopsy. Am J Cardiol 1984;53:980-981

72. Coleman RA, Winter HS, Wolf B, Gilchrist JM, Chen YT. Glycogen storage disease type III (glycogen debranching enzyme deficiency): correlation of biochemical defects with myopathy and cardiomyopathy. Ann Intern Med 1992;116:896-900.

73. Carvalho JS, Matthews EE, Leonard JV, Deanfield J. Cardiomyopathy of glycogen storage disease type III. Heart Vessels 1993;8:155-159.

74. Talente GM, Coleman RA, Alter C, et al. Glycogen storage disease in adults. Ann Intern Med 1994;120:218-226.

75. Akazawa H, Kuroda T, Kim S, Mito H, Kojo T, Shimada K. Specific heart muscle disease associated with glycogen storage disease type III: clinical similarity to the dilated phase of hypertrophic cardiomyopathy. Eur Heart $J$ 1997; 18:532-533

76. Rossignol AM, Meyer M, Rossignol B, Palcoux MP, Raynaud EJ, Bost M. [Glycogenosis type III myocardiopathy]. Arch Fr Pediatr 1979;36:303-309.

77. Cochrane AB, Fedson SE, Cronin DC II. Nesiritide as bridge to multi-organ transplantation: a case report. Transplant Proc 2007;39:308 -310.

78. Levine JC, Kishnani PS, Chen YT, Herlong JR, Li JS. Cardiac remodeling after enzyme replacement therapy with acid alpha-glucosidase for infants with Pompe disease. Pediatr Cardiol 2007;29:1033-1042.

79. Ogimoto A, Okubo M, Okayama H, et al. A Japanese patient with cardiomyopathy caused by a novel mutation R285X in the AGL gene. Circ $J$ 2007;71:1653-1656.

80. Smit GP, Fernandes J, Leonard JV, et al. The long-term outcome of patients with glycogen storage diseases. J Inherit Metab Dis 1990;13:411-418.

81. Keddad KRS, Baussan C, Chalas J, et al. Blood lipids and rheological modifications in glycogen storage disease. Clin Biochem 1996;29:73-78.

82. Hershkovitz E, Donald A, Mullen M, Lee PJ, Leonard JV. Blood lipids and endothelial function in glycogen storage disease type III. $J$ Inherit Metab Dis 1999;22:891- 898.

83. Fernandes J, Leonard JV, Moses SW, et al. Glycogen storage disease: recommendations for treatment. Eur J Pediatr 1988;147:226-228.

84. Goldberg T, Slonim AE. Nutrition therapy for hepatic glycogen storage diseases. J Am Diet Assoc 1993;93:1423-1430.

85. Slonim AE, Coleman RA, Moses WS. Myopathy and growth failure in debrancher enzyme deficiency: improvement with high-protein nocturnal enteral therapy. J Pediatr 1984;105:906-911.

86. Slonim AE, Weisberg C, Benke P, Evans OB, Burr IM. Reversal of debrancher deficiency myopathy by the use of high-protein nutrition. Ann Neurol 1982;11:420-422.

87. Borowitz SM, Greene HL. Cornstarch therapy in a patient with type III glycogen storage disease. J Pediatr Gastroenterol Nutr 1987;6:631- 634

88. Mundy HR, Williams JE, Lee PJ, Fewtrell MS. Reduction in bone mineral density in glycogenosis type III may be due to a mixed muscle and bone deficit. J Inherit Metab Dis 2008;31:418-423.

89. Lee PJ, Ferguson C, Alexander FW. Symptomatic hyperinsulinism reversed by dietary manipulation in glycogenosis type III. J Inherit Metab Dis 1997;20:612-613.

90. Dagli AI, Zori RT, McCune H, Ivsic T, Maisenbacher MK, Weinstein DA. Reversal of glycogen storage disease type IIIa-related cardiomyopathy with modification of diet [published online ahead of print March 30, 2009]. $J$ Inherit Metab Dis doi: 10.1007/s10545-009-1088-x. 
91. Portmann B, Thompson RJ, Roberts EA, Paterson AC. Genetic and metabolic liver disease, 5 ed. London: Churchill Livingstone; 2007.

92. Cosme A, Montalvo I, Sanchez J, et al. [Type III glycogen storage disease associated with hepatocellular carcinoma]. Gastroenterol Hepatol 2005;28: $622-625$.

93. Shimizu J, Shiraishi H, Sakurabayashi S, et al. [A report on an adult case of type III glycogenosis with primary liver cancer and liver cirrhosis]. Nippon Shokakibyo Gakkai Zasshi 1982;79:2328-2332.

94. Wiesner R, Edwards E, Freeman R, et al. Model for end-stage liver disease (MELD) and allocation of donor livers. Gastroenterology 2003;124:91-96.

95. Merion RM, Schaubel DE, Dykstra DM, Freeman RB, Port FK, Wolfe RA. The survival benefit of liver transplantation. Am J Transplant 2005;5:307313.

96. Davis MK, Weinstein DA. Liver transplantation in children with glycogen storage disease: controversies and evaluation of the risk/benefit of this procedure. Pediatr Transplant 2008;12:137-145.

97. Iyer SG, Chen CL, Wang CC, et al. Long-term results of living donor liver transplantation for glycogen storage disorders in children. Liver Transpl 2007; $13: 848-852$.

98. Moses SW, Gadoth N, Bashan N, Ben-David E, Slonim A, Wanderman KL. Neuromuscular involvement in glycogen storage disease type III. Acta Paediatr Scand 1986;75:289-296.

99. Tolun AA, Boyd KF, Austin SL, et al. Utility of a urinary tetrasaccharide as a biomarker for glycogen storage disease type III. In: 11th International Congress of Inborn Errors of Metabolism (ICIEM), San Diego, California; 2009

100. Marbini A, Gemignani F, Saccardi F, Rimoldi M. Debrancher deficiency neuromuscular disorder with pseudohypertrophy in two brothers. $J$ Neurol 1989;236:418-420.

101. Parvari R, Moses S, Shen J, Hershkovitz E, Lerner A, Chen YT. A single-base deletion in the 3 -coding region of glycogen-debranching enzyme is prevalent in glycogen storage disease type IIIA in a population of North African Jewish patients. Eur J Hum Genet 1997;5:266-270.

102. Kiechl S, Willeit J, Vogel W, Kohlendorfer U, Poewe W. Reversible severe myopathy of respiratory muscles due to adult-onset type III glycogenosis. Neuromuscul Disord 1999;9:408-410.

103. Haller RG, Vissing J. Functional evaluation of metabolic myopathy. In Engel AG, Franzini-Armstrong C, editors. Myology. New York, NY: McGraw Hill; 2004:665-679.

104. Haller RG, Wyrick P, Taivassalo T, Vissing J. Aerobic conditioning: an effective therapy in McArdle's disease. Ann Neurol 2006;59:922-928.

105. Chan JC, Cockram CS, Critchley JA. Drug-induced disorders of glucose metabolism. Mechanisms and management. Drug Saf 1996;15:135-157.

106. Oki Y, Okubo M, Tanaka S, Nakanishi K, Kobayashi T, Murase T. Diabetes mellitus secondary to glycogen storage disease type III. Diabet Med 2000;17:810-812

107. Giannitrapani L, Soresi M, La Spada E, Cervello M, D'Alessandro N, Montalto G. Sex hormones and risk of liver tumor. Ann N Y Acad Sci 2006;1089:228-236.

108. Mairovitz V, Labrune P, Fernandez H, Audibert F, Frydman R. Contraception and pregnancy in women affected by glycogen storage diseases. Eur J Pediatr 2002;161(suppl 1):S97-S101.

109. Bahamondes L, Monteiro-Dantas C, Espejo-Arce X, et al. A prospective study of the forearm bone density of users of etonorgestrel- and levonorgestrel-releasing contraceptive implants. Hum Reprod 2006;21:466-470.

110. Lee P. Successful pregnancy in a patient with type III glycogen storage disease managed with cornstarch supplements. Br J Obstet Gynaecol 1999; 106:181-182.

111. Ngai SH. Effects of anesthetics on various organs. $N$ Engl J Med 1980; 302:564-566.

112. Mohart D, Russo P, Tobias JD. Perioperative management of a child with glycogen storage disease type III undergoing cardiopulmonary bypass and repair of an atrial septal defect. Paediatr Anaesth 2002;12:649-654.

113. Roe CR, Mochel F. Anaplerotic diet therapy in inherited metabolic disease: therapeutic potential. J Inherit Metab Dis 2006;29:332-340.

114. Gregory BL, Shelton GD, Bali DS, Chen YT, Fyfe JC. Glycogen storage disease type IIIa in curly-coated retrievers. J Vet Intern Med 2007;21: $40-46$ 